\title{
La voz de Dios y la respuesta awajún. El caso de la Iglesia Bíblica Awajún en el Alto Marañón (Amazonía peruana)
}

La voix de Dieu et la réponse awajún. Le cas de l'Église Biblique Awajún dans le Haut Marañón (Amazonie péruvienne)

The voice of God and the Awajún answer. The case of the Biblical Church Awajún in the Upper Marañón drainage (Peruvian Amazon)

\section{Silvia Romio}

\section{(2) OpenEdition}

Journals

Edición electrónica

URL: http://journals.openedition.org/bifea/10148

DOI: 10.4000/bifea.10148

ISSN: 2076-5827

\section{Editor}

Institut Français d'Études Andines

\section{Edición impresa}

Fecha de publicación: 8 diciembre 2018

Paginación: 247-266

ISSN: 0303-7495

Referencia electrónica

Silvia Romio, «La voz de Dios y la respuesta awajún. El caso de la Iglesia Bíblica Awajún en el Alto Marañón (Amazonía peruana) », Bulletin de l'Institut français d'études andines [En línea], 47 (3)| 2018 Publicado el 08 diciembre 2018, consultado el 04 noviembre 2020. URL : http:// journals.openedition.org/bifea/10148; DOI : https://doi.org/10.4000/bifea.10148

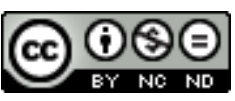

Les contenus du Bulletin de l'Institut français d'études andines sont mis à disposition selon les termes de la licence Creative Commons Attribution - Pas d'Utilisation Commerciale - Pas de Modification 4.0 International. 


\title{
La voz de Dios y la respuesta awajún. El caso de la Iglesia Bíblica Awajún en el Alto Marañón (Amazonía peruana)
}

\author{
Silvia Romio*
}

\begin{abstract}
Resumen
Mientras que en numerosos grupos de la Amazonía peruana el discurso mesiánico del líder predicador mantiene un cierto éxito, entre los awajún del Alto Marañón ese tipo de liderazgo se presenta actualmente como un recurso poco llamativo. Pero no fue siempre así. Entre los años 1970 y 1980, la ilusión de devenir «líder religioso» atrajo a una buena cantidad de jóvenes que se dejaron guiar por Thomas Dati, un pastor awajún promotor de la que sería la Iglesia Autónoma Awajún, primer ejemplo de este tipo en la provincia de Imaza (región Amazonas). Esta realidad religiosa, fruto del sincretismo entre las perspectivas awajún y evangélica, logró alcanzar en poco tiempo un número importante de adeptos. ¿Quién fue ese predicador y qué tipo de mensaje profesaba? ¿Cuáles fueron las razones de su éxito y por qué su derrumbe? A lo largo del presente artículo, a través de un trabajo de etnohistoria que reúne fuentes escritas y memorias orales, busco reconstruir algunos de los principales aspectos que caracterizaron esta singular experiencia y las herencias que ella dejó en la realidad cultural local.
\end{abstract}

Palabras claves: Amazonía, awajún, Iglesia Autónoma Awajún, Alto Marañón, conversión evangélica, Thomas Dati, Misión Suiza, kakajam moderno

\section{La voix de Dieu et la réponse awajún. Le cas de l'Église Biblique Awajún dans le Haut Marañón (Amazonie péruvienne)}

\section{Résumé}

Alors que dans de nombreux groupes d'Amazonie péruvienne le discours messianique du leader religieux continue de rencontrer un certain succès, chez les Awajún du Haut Marañón ce modèle de leadership ne suscite plus l'engouement des populations. Mais il n'en fut pas toujours ainsi. Dans les années 1970-1980, l'espoir de devenir des leaders religieux a mobilisé de nombreux jeunes Awajún

Doctora en Estudios Políticos y Magister en Antropología Cultural. Asociada a la Pontificia Universidad Católica del Perú (PUCP): Avenida Universitaria 1801, San Miguel, Lima (Perú) / École 
qui ont suivi le pasteur Thomas Dati, fondateur de la première Église Autonome Awajún dans la province d'Imaza (région Amazonas). Sa parole, fruit d'un syncrétisme entre la cosmologie awajún et le discours évangélique, réussit à réunir un nombre important d'adeptes en peu de temps. Qui fut ce prédicateur et quelle était la teneur de son message ? Quelles furent les raisons de son succès et de sa chute ? Grâce à une approche ethno-historique fondée sur des sources écrites et sur la mémoire orale, nous proposons de révéler dans cet article les aspects les plus importants de cet épisode singulier et l'héritage qu'ils ont laissé dans la réalité culturelle locale.

Mots-clés : Amazonie, Awajún, Haut Marañón, Église Autonome Awajún, conversion évangelique, Thomas Dati, Mission Suisse, kakajam moderne

\title{
The voice of God and the Awajún answer. The case of the Biblical Church Awajún in the Upper Marañón drainage (Peruvian Amazon)
}

\begin{abstract}
Among many groups in the Peruvian Amazon, the messianic speech promoted by a preacher leader achieves some success. In contrast, among the Awajún of the Upper Marañón this type of leadership does not receive particular attention. However, it has not always been this way. There was a time, between the '70s and' 80s, when the expectation of becoming "religious leader" attracted a good number of young people, who let themselves be guided by Thomas Dati, a Awajún pastor who was the founder of the first instance of Autonomous Awajún Church in the province of Imaza (Amazonas region). This religion, the result of syncretism between the Awajún cultural perspective and the evangelical message, was able to attract a large number of followers in a short period of time. Who was this preacher and what kind of message was he spreading? What were the reasons for his success and for his fall? In this article, thanks to ethnohistoric work brings together written sources with oral memories, we recreate some of the main aspects of this forceful experience as well examining the legacy that he left within the local cultural reality.
\end{abstract}

Keywords: Amazonía, Awajún, Upper Marañón, Autonomus Awajún Church, evangelical conversion, Thomas Dati, Switzerland Mission, modern kakajam

\section{INTRODUCCIÓN}

«No es importante la religión, lo importante es llegar a la Palabra de Dios» (Silvano Dati Puanchig, comunidad Centro Wawik, junio de 2017).

Hace cien años se rompió en el Perú el monopolio oficial de la Iglesia Católica. La reforma constitucional de 1915 formalizó, por vez primera, la actividad proselitista de diversas organizaciones cristianas que, desde décadas anteriores, habían mantenido sus actividades en los márgenes de la legalidad, frente a un Estado que seguía afirmando su confesionalidad. Desde entonces, la expansión

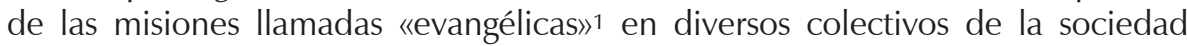

des Hautes Études en Sciences Sociales - Laboratoire CESPRA, 105 Bd. Raspail, Paris. Email: silvia. romio@gmail.com

1 Llamamos «grupos evangélicos» un conjunto de expresiones religiosas de origen cristiano surgido a partir del siglo XIX, que en América Latina se expande desde los comienzos del siglo XX, y particularmente en espacios urbano-marginales y entre grupos indigenas. «El protestantismo evangélico se define mejor como una tradición que se distingue por tres creencias, que incluyen: 
nacional, urbanos, rurales e indígenas, terminó generando una serie de cambios estructurales que hoy se evidencian en el complejo panorama sociorreligioso peruano.

Enfocándonos en el contexto amazónico y, particularmente, en la zona del Alto Marañón2, en la frontera entre el Perú y el Ecuador, vemos que este proceso ha provocado un cambio sustancial entre los awajún de la región, desencadenando procesos de transformación hasta ahora vigentes. No se trataría solamente de una reformulación de los modos de expresión y de las actitudes cotidianas, sino principalmente de sus formas de pensar y de definir al «individuo adulto awajún» así como su posición dentro de la sociedad actual. En lugar de una «conversión religiosa» 3 , observamos una reformulación particular y localmente definida del mensaje religioso a través de las prácticas, las perspectivas y el pensamiento propios de los awajún.

En mis anteriores investigaciones, he propuesto algunas reflexiones sobre las dinámicas que llevaron, a partir de los años 1950, a la definición de la figura del «dirigente indígena» entre los awajún del Alto Marañón, es decir a las prácticas y los discursos que pasaron a caracterizar el estatus de poder de los llamados «líderes modernos». Numerosos son los casos que han puesto a la luz el rol prioritario jugado por el vínculo personal que muchos jóvenes habían establecido con los misioneros evangélicos (y católicos) en la construcción del liderazgo indígena contemporáneo, sobre todo durante sus estudios escolares (Romio, 2017: 248-252).

En el presente trabajo, quisiera proponer una reflexión sobre el escenario que se creó entre los años 1960 y 1990, de convivencia entre múltiples facetas y diferentes formas de personalización del «liderazgo moderno» en esta zona. En un clima marcado por fuertes cambios sociales, influencias externas y procesos de hibridación, la figura del «dirigente indígena» puede presentarse como una de las posibles definiciones del «individuo adulto moderno» entre los awajún. Antes de la cristalización en la identificación del «kakajam4 moderno» con el «dirigente indígena», hubo una etapa de experimentación e hibridación entre las expectativas locales y los modelos externos para la representación del poder. En el curso de este proceso, tuvo un cierto éxito la figura del «líder religioso» propuesta por el pastor awajún Thomas Dati. Sabemos que varios fueron los jóvenes atraídos por el modelo del «indígena profeta» que buscaron adaptar un estilo de vida que

1. la completa confiabilidad y autoridad final de la Biblia, 2. la necesidad de salvación a través de una relación personal con Jesúcristo, con frecuencia experimentada en términos de "renacer", y 3. la importancia de propagar este mensaje de salvación a toda nación y persona, un deber al que se refiere con frecuencia como la Gran Comisión (Stoll, 1990 : 16)».

2 Dicha zona corresponde a la provincia de Bagua (región Amazonas).

3 Una reflexión sobre el tema de la «conversión religiosa» entre los awajún, sus problemáticas y sus formas de expresión se encuentra en la sección 5 del presente artículo.

4 Kakajam: «Hombre fuerte, valiente, impávido frente a la muerte, hábil estratega, virtuoso en la construcción de la retórica, generoso en la hospitalidad, obstinado en la venganza» (Descola, 1993: 174, traducción propia). 
conjugaba las prácticas religiosas con un discurso mesiánico y de reivindicación étnica. Un grupo de awajún se adscribió a las filas del Instituto Bíblico Awajún de Yamacay (IBAY) fundado por Thomas Dati en las orillas del Marañón, en el distrito de Nieva. Sin embargo, en la actualidad las evidencias etnográficas muestran que este tipo de figura no perduró, y hoy en día queda como un recuerdo del pasado. ¿Quién fue ese predicador y cuál era el mensaje religioso ahí profesado? En este artículo buscaré reconstruir, a través de fuentes escritas y memorias orales, algunos de los principales aspectos que caracterizaron esta peculiar experiencia y las herencias en términos de identidad cultural y religiosa que se transmitieron a sus adeptos.

\section{LA «LLEGADA» DE LA MISIÓN NAZARENA ENTRE LOS AWAJÚN: UNA NUEVA FORMA DE EXPRESIÓN DEL PODER}

Al reconstruir la historia de la «evangelización» de la región, vemos que la penetración religiosa, tanto católica como evangélica, entre los awajún del Alto Marañón, se volvió permanente y estructurada solo a partir de la mitad del siglo pasado (Guallart, 1990; Brown, 2014: 217-218). La pionera experiencia de la misión Nazarena, fundada en el actual distrito de Imaza por Roger Winans al comienzo de los años 1920, tuvo un fuerte impacto en esa sociedad indígena, tanto por la fuerza de voluntad del misionero, como por sus modalidades de integración en la zona. El pastor americano, en alianza con los jefes indígenas, logró establecer relaciones de intercambio a diferentes niveles: de un lado, el ya consolidado trueque de recursos naturales a cambio de fusiles, municiones y ropas; del otro, la construcción de espacios laborales donde los indígenas cumplían con múltiples roles y funciones.

Dentro de una dinámica fuertemente vertical y jerarquizada, Winans consolidó la presencia indígena en todas las actividades que caracterizaban la vida económica y religiosa de la naciente misión. Este clima permitió la formación de figuras preparadas para sus diversos sectores de producción como el manejo del almacén, el cultivo de los campos y el cuidado del ganado (Romio, 2017: 144-147; Winans, 1955: 33-37). Podemos añadir, además, la participación de los indígenas en los espacios religiosos, en las primeras y rudimentarias escuelas, en las actividades de proselitismo y, sobre todo, acompañando al misionero en sus viajes recurrentes a la ciudad. Estas experiencias empezaron a ser reconvertidas en términos de poder y autoridad al interior de su grupo familiar. Efectivamente, podemos notar el desenvolvimiento de un proceso conjunto, donde las necesidades de una misión emergente se encontraron con las ambiciones de los jóvenes indígenas a la búsqueda de experiencias de formación particulares y formas de aprendizaje distintas, consideradas como herramientas principales para la definición de un poder personal en tanto que kakajam (Mader, 1999: 419).

El éxito de la misión nazarena, sin embargo, estuvo limitado por los ciclos de expansión y recesión del caucho. Hacia la mitad del siglo pasado, una temprana etapa de explosión religiosa y expansión comercial fue seguida por otra de retiro 
y de pérdida de autoridad y control social de la misión sobre los indígenas en toda la región. De todas maneras, esta experiencia había dejado una huella importante en todos los grupos indígenas que se habían acercado a la misión, cambio particularmente visible tanto a nivel de prácticas cotidianas como, sobre todo, en las expresiones individuales (Priest, 2003). Una de las consecuencias más significativas se encuentra en las diferentes modalidades de exhibición del poder kakajam que empezaron a circular entre los líderes indígenas de la zona, fruto del Connubio entre prácticas awajún y el performance propio de los predicadores evangélicos. La figura del misionero, con sus saberes, su poder económico proveniente de las actividades comerciales desempeñadas en la misión y su capacidad de moverse en espacios geográficos y culturales distintos, se convirtió en un modelo de autoridad y prestigio fuertemente atractivo entre los indígenas. Muchos de los awajún que habían desempeñado un rol como intermediarios culturales y acompañantes del pastor, parecían interesados en reinterpretar de forma autónoma su gestualidad y sus expresiones, terminando por producir algo más que una simple mímesis.

Siguiendo el desenvolvimiento de las historias de vida de estos jóvenes, encontramos que, a mediado del siglo XX, sus nombres aparecen entre los líderes indígenas emergentes en toda la región, escogidos por los lingüistas del Instituto Lingüístico de Verano (ILV) para ser promotores de realidades educativas innovadoras, como las escuelas bilingües. En otras palabras, podemos notar una continuidad entre las figuras dotadas por los nazarenos de facilidades para el manejo de actividades productivas, y el sucesivo acceso a los espacios de formación profesional como profesores bilingües, ofrecidos por el ILV. Podemos observar cómo esta acumulación de experiencias había garantizado un conjunto de conocimientos, prácticas y expresiones lingüísticas únicas, que rápidamente pasó a ser reformulado en nuevas expresiones del poder kakajam, donde, por un tiempo, la figura del «profesor bilingüe» o del «enfermero profesional», fue acompañada también por la del «predicador indígena», o del «líder religioso».

\section{UNA EXPERIENCIA PARTICULAR: LA IGLESIA BÍBLICA AWAJÚN}

En los años 1980 Michael Brown escribía que la característica peculiar de los awajún era la capacidad de incorporar con facilidad elementos culturales externos y, a través de un trabajo de readaptación, transformarlos en herramientas específicas para la reproducción de su particular forma de ver y entender el mundo (Brown, 1986: 183). Estas palabras siguen siendo las más adecuadas para entender la dinámica de hibridación religiosa y adaptación cultural que se desarrolló entre los awajún del Alto Marañón a lo largo de la segunda mitad del siglo XX (Brown, 1984 : 215; Brown, 2014: 247-248). Entre las diferentes realidades que nacieron del encuentro entre el universo cultural awajún y los esfuerzos de evangelización, me interesaré en particular por el caso de la Iglesia Bíblica Awajún. Tal como su nombre lo indica, se trató de una Iglesia autónoma, que nació en la década de 
1970 por iniciativa de Thomas Dati (véase fig. 1), un awajún originario de la zona denominada Chiangos ${ }^{5}$ quien, en su juventud, había tenido una cercanía con las diferentes Iglesias evangélicas presentes en la región, es decir la misión Nazarena, la Misión Suiza y, sucesivamente, con el ILV.

En los datos reportados por el antropólogo Robert Priest, quien estudió en profundidad el desarrollo de esta Iglesia entre 1987 y 1989 (Priest, 1993), encontramos la descripción de una realidad que asombra por el número de adeptos, la complejidad del discurso religioso propuesto por su fundador y el tipo de actividades desempeñadas. En sus textos, Priest enumera 60 comunidades relacionadas con la Iglesia de Dati. Entre ellas, 120 representantes se reunían periódicamente, en la sede en Tundusa (Priest, 1993: 5)6. Entre 2016 y 2017, pude confirmar las cifras elaboradas por Priest a través de testimonios orales recolectados durante mi trabajo de campo en algunas de las comunidades donde sigue vigente la Iglesia Bíblica Awajún7; además, he podido encontrar a algunos de los principales adeptos de Dati que habían participado en la etapa de fundación de la Iglesia 8 .

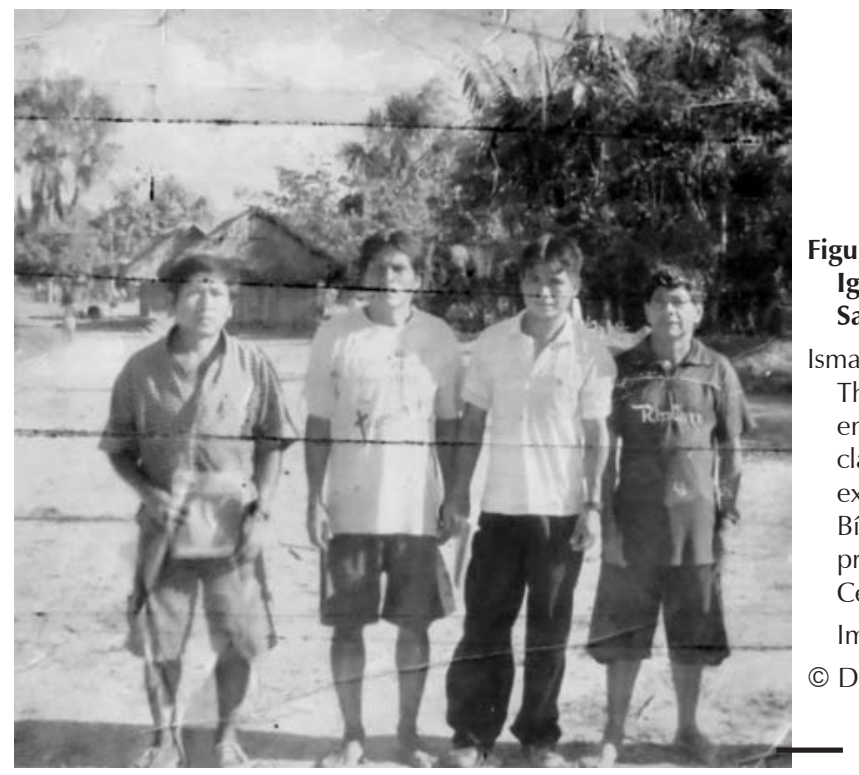

Figura 1 - Miembros de la Iglesia Bíblica Awajún en San Pablo

Ismael Dati Puanchig (hijo de Thomas Dati) es la persona en el centro, con camisa clara y pantalón largo. Foto expuesta dentro de la Iglesia Bíblica Awajún actualmente presente en la comunidad Centro Wawiko (distrito de Imaza)

(C) Desconocido

5 Distrito del Cenepa, provincia de Condorcanqui (región Amazonas).

6 Hay que considerar que, durante la investigación de Priest, a finales de los años 1980, la Iglesia Bíblica Awajún ya estaba en una etapa de crisis y fragmentación interna. Supuestamente, en la década anterior, el número de sus feligreses pudo haber sido el doble o más.

7 Comunidades nativas presentes a lo largo del río Wawik, afluente del Marañón, presentes en el distrito de Imaza.

8 Esta investigación contará, en particular, con los testimonios de cuatro adeptos de la Iglesia Bíblica Awajún, y seguidores de Thomas Dati. Es decir, de dos de sus hijos, Isaías y Silvano Dati, y de dos de los primeros adeptos de la Iglesia, el múun Marciano D. y Gerónimo T. Además, se han reunido 
Priest describe el fenómeno de la conversión de este grupo como algo más profundo y complejo que una simple ruptura con su universo cultural anterior. Las ceremonias a las cuales asistió, así como las prácticas religiosas individuales, testimonian el aflorar de una forma particular de readaptación del universo conceptual y lingüístico cristiano con la perspectiva cultural awajún (Priest, 2007: 148). La vida de la comunidad de Tundusa se desempeñaba alrededor de las «prácticas religiosas» de la Iglesia, es decir, toda una serie de acciones que conjugaban antiguas costumbres awajún con formas de expresión de una fe de clara matriz cristiana. Es por ello que, por ejemplo, encontramos descripciones de las actividades dedicadas al cultivo de plantas particulares y un interés específico por la toma matutina de brebajes como la wayusa. A ello se juntaban varios momentos dedicados al estudio de la Biblia y del castellano, la lectura de textos sagrados, los momentos de oración colectiva, los intercambios de saberes entre los hombres mayores y la participación en ceremonias masivas. Todo esto se desarrollaba principalmente en idioma awajún. En la primera etapa de la Iglesia existió un espacio de formación de jóvenes, el Instituto Bíblico Awajún de Yamacay (IBAY), orientado a formar futuros pastores indígenas. Los recuerdos de quienes, en su momento, participaron en esa escuela, nos permiten imaginar una realidad emblemática, fruto de un vínculo entre el internado y las prácticas de formación de los «hombres fuertes» (kakajam), propias de los awajún (Brown, 1986: 126127; Greene, 2009: 87).

Era el 1977. Sesenta alumnos fueron. Pero parece que el Señor estaba escogiendo. A través de las enfermedades, todos los estudiantes estaban infectados, habían caído con fiebre, y yo también. Pero a mi, de retroceder no tenía idea. Yo estaba decidido. [...] En los primeros años estábamos ahí nueve meses, alejados de la familia. Teníamos que trabajar en la chacra, construir casitas, tres en total, y una era del hermano Thomas... Yamacay estaba todo lleno de palos trozados. Y luego subir a la montaña, a estudiar, por la tarde. Íbamos en grupo de tres o cuatro. Tomar toé u otras plantas. Por largos periodos. Uy! iqué sufrimiento! Aún así, nunca me fui detrás (Marcial D., Bagua, julio de 2017).

Como decíamos anteriormente, entre las principales actividades de la Iglesia encontramos un interés particular en la realización de funciones religiosas capaces de reunir un número importante de adeptos, provenientes de todas las comunidades afiliadas. Gracias a las descripciones propuestas por Priest (Priest, 1993: 7; 2007), podemos saber que en esos espacios se realizaba una interesante síntesis entre actividades propias de una función religiosa cristiana con aspectos característicos de un Ipáamamu9, es decir una forma de organización awajún orientada hacia la realización de un trabajo colectivo. En dichos contextos, se celebraba la cosecha de la planta de wayusa y se entonaban cantos colectivos,

diferentes fuentes orales, tanto con los actuales adeptos de la Iglesia (comunidades de Centro Wawik y San Pablo), como con conocidos de Thomas Dati, actualmente residentes en el distrito de Imaza (comunidades de Nazareth y de Yamayakat).

9 Ipáamamu: «todos unidos» (Brown, 1984: 108). 
donde los instrumentos y las melodías propias de la tradición musical awajún venían adaptados a los textos de los cánticos cristianos (Priest, 2007: 151).

El interés de sus adeptos en enfatizar, a través de prácticas y discursos, un carácter de autonomía y autenticidad en términos de «identidad étnica», constituye un aspecto principal. Entre las voces de los recuerdos, hay una convicción de que participar en esta Iglesia, y seguir sus actividades, permitía a sus adeptos alcanzar una condición de «verdadero aguaruna» (Priest, 1993: 6; 2007: 148) .

Mi padre no se sentía contento. Siempre tenía la sensación que faltaba algo. Un día, mientras traducía el evangelio de Juan, encontró el paso del evangelio que decía... [...] Y entendió que tenía que crear un espacio para volver a ser auténticos aguarunas en la luz de Cristo Jesús (Silvano Dati, Centro Wawik, junio de 2017).

Estas palabras nos transmiten informaciones importantes sobre una de las razones que motivaron a los awajún a adherirse a esta Iglesia. En primer lugar, existe un real interés en «revitalizar» costumbres propias de la sociedad awajún, marginalizadas por la anterior experiencia con la Iglesia nazarena o el contacto con la sociedad externa. Como sabemos, gracias a etnografías anteriores sobre los grupos jíbaros, las prácticas de tomas de wayusa y ayahuasca caracterizaban el equilibrio sociocultural cotidiano de estos grupos, y reunían diferentes finalidades a la vez. De un lado, garantizaban un lavado estomacal funcional para el bienestar físico de las personas; del otro, permitían consolidar espacios de sociabilidad y de autoridad entre grupos de edad específicos (Mader, 1999: 67-68; Brown, 1984: 176). Además de los beneficios físicos, participar en estas actividades matutinas tenía un significado importante en términos de ascensión a un determinado estatus social, la de hombre adulto o múun. Efectivamente, dichos momentos se acompañaban de largas conversaciones sobre los sueños y visiones obtenidas en la noche, recuerdos que eran objeto de reflexión y análisis, que permitían tomar decisiones sobre las actividades diurnas, tanto de carácter individual como colectivo (Descola, 1993: 122-139; Brown, 1984: 108, 211). Si los círculos de toma de wayusa y de conversación sobre el pasado, histórico y onírico, viene descrito como un lugar estrictamente masculino, no debemos olvidar que toda la etapa de cultivo de la planta y de preparación del brebaje se marcaba como un campo dominado por los saberes femeninos, donde la mujer guiaba el crecimiento de la planta y su florescencia a través de curas específicas y de cantos mágicos (Brown, 1986: 124). Priest mismo señala cómo los adeptos de la Iglesia Bíblica Awajún tenían interés en recuperar cantos y saberes botánicos, aspectos que aseguraban la permanencia de estas prácticas, además de permitir la renovación de la identidad del grupo (Priest, 2007:137).

Como sabemos, para muchas sociedades amazónicas, las prácticas que llevan a la construcción del cuerpo constituyen uno de los ejes principales en las acciones cotidianas (Seeger et al., 1979). Apareçida Vilaça, en sus estudios sobre los wari', insiste en la atención particular acordada a las prácticas que permiten confirmar periódicamente lo «humano», separándolo de lo «no humano». Se trataría, por lo tanto, de una humanidad que necesita constantemente ser confirmada 
a través de acciones específicas que condicionan el cuerpo, su alimentación y sus fluidos (Vilaça, 2005: 454). Siguiendo esta perspectiva, podemos entender cómo, entre los awajún del Alto Marañón, determinadas prácticas permitían la reconfirmación cíclica del individuo como parte de ese grupo: la toma de ciertas plantas garantizaba, por lo tanto, no solamente la transmisión de saberes particulares, sino también la construcción de cuerpos marcados por el flujo de sustancias específicas.

Volviendo a la realidad del Alto Marañón, entendemos que la Iglesia Bíblica Awajún consideraba entre sus prioridades definir un espacio de consolidación de la identidad del grupo, a través de un conjunto de acciones orientadas a reunir prácticas locales con expresiones y actividades aprendidas del trato y convivencia con los misioneros. ¿Cuál sería entonces el vínculo que se establece entre uno y otro? Aparentemente, para los nuevos adeptos, se abría la posibilidad de reproducir ritualidades que la misión nazarena había prohibido, construyendo actividades que reafirmaban la «independencia y autonomía» social y cultural que la Iglesia autónoma proponía. En otras palabras, los awajún se han apropiado de formas de expresión y de exhibición del poder propias de la misión americana, además de un manejo de saberes relacionados con una fuente de poder inédito, el libro sagrado. En las etapas sucesivas, los «líderes religiosos» serán los que lograrán adaptar estos elementos a las expectativas de la sociedad awajún: el transformar el contenido mismo de los saberes recientemente adquiridos en formas de expresión de las prácticas locales habituales ${ }^{10}$.

\section{THOMAS DATI, LA VOZ DE DIOS}

El principal artífice de esta obra de sincretismo llamada Iglesia Bíblica Awajún fue Thomas Dati. Luego de un largo periodo de colaboración con la Misión Suiza y el ILV, y de formación en el Instituto Bíblico de Huánuco, Thomas Dati fundó a comienzos de los años 1970 el Instituto Bíblico Awajún en la comunidad de Yamacay (IBAY)11. Situada a orillas del río Marañón, cerca de Orakusa, esta primera sede de la Iglesia se encontraba en un lugar estratégico: por su proximidad de la confluencia entre los ríos Marañón y Nieva, constituía uno de los principales puntos de intercambio comercial de toda la región, acompañado tanto por la cercanía con la misión de Santa Maria de Nieva como por la presencia de la base militar

${ }^{10}$ Es importante mencionar el rol jugado por la Misión Suiza en todas las etapas de construcción y realización de la Iglesia. Al margen de una realidad «puramente indígena», hay que recordar la presencia de una serie de misioneros «alemanes» que guiaron la formación de Thomas Dati y los primeros pasos de la Iglesia. Entender en profundidad el tipo de aporte y el grado de presencia jugado por la Misión Suiza en la definición de la identidad de la Iglesia Bíblica Awajún necesitaría un artículo a parte.

11 Esta Iglesia asumió nombres diferentes a lo largo del tiempo: en una primera etapa, cuando estaba ubicada en la comunidad de Yamacay, se llamó Instituto Bíblico Awajún Yamacay (IBAY). Sucesivamente, con sede en Antiguo Kanaan y Tundusa, se llamó Iglesia Bíblica Awajún. Desde los años 1990, tiene su sede en San Pablo, y se llama Escuela Bíblica Awajún del Alto Marañón (EBAAM). 
«Ciro Alegría». Sin embargo, Yamacay constituye solamente el punto de partida de un trabajo de proselitismo expandido por toda la región. Efectivamente, el trabajo pastoral de Dati consistía en viajar de una comunidad a otra, reuniendo a los múun, y en hablarles de Dios y de los proyectos de su nueva Iglesia. Su discurso apuntaba a una reafirmación de la autonomía de la identidad awajún con aproximación a los textos sagrados y a una relación con lo divino.

Es importante notar cómo la fundación de un espacio de formación de los jóvenes - en cuanto lugar de construcción de una identidad fuerte y nueva— se posiciona al centro de su discurso pastoral.

Según las fuentes orales, el gran éxito que acogió el discurso de Dati, así como la afluencia constante de fieles que él atraía a Yamacay, ocasionaron ciertas desavenencias con los otros miembros (católicos) de la comunidad, a tal punto de obligar al predicador a buscar una nueva sede. Así, Dati abandona Yamacay y cierra el instituto. En los años siguientes se concentró en la fundación de diferentes centros religiosos a lo largo del Marañón. También la sede principal de la Iglesia cambió de lugar en el curso del tiempo: la comunidad de Nuevo Kanaam, luego la de Tundusa y, finalmente, la de San Pablo, todas aún existentes en los actuales distritos de Nieva y de Imaza. Estos continuos cambios de sede son los indicadores del irrefrenable proceso de fragmentación de la Iglesia que difícilmente iba encontrando espacios idóneos para sus proyectos de proselitismo. A esto se sumaba la progresiva decaída física y de fuerza política de su fundador.

En la década de 1990, Dati fundó la Escuela Bíblica Aguaruna del Alto Marañón (EBAAM) en la comunidad de San Pablo (véase fig. 2)12, con el objetivo de impartir una formación acerca de los textos bíblicos y, a la vez, ofrecer un espacio de acogida y encuentro para los miembros y familias afiliados a su Iglesia. A esas alturas, el proyecto de construcción de un instituto de formación de jóvenes pastores indígenas, miembros de la Iglesia, ya no es parte de las propuestas y quedará tan solo en los recuerdos de sus primeros adeptos13.

Siguiendo con la historia de vida de Dati, vemos que sus hijos suelen recordarlo como «un orador excepcional, dotado de un don particular con las palabras» (Silvano Dati Puanchig, Centro Wawik, julio de 2017). Uno de sus principales adeptos dice que Dati «era reconocido como "misionero", porque era el primero en hablar de la palabra de Dios. iY cómo hablaba de Dios!» (David T., comunidad de Nazareth, junio de 2017).

Estas expresiones nos permiten entender cómo la figura de Dati supo impactar en los demás awajún, tanto por sus capacidades oratorias como por las expresiones y las gestualidades que adoptó. Como Lowie y Clastres lo describen muy bien, las capacidades oratorias son las primeras que distinguen a un líder exitoso (Clastres, 1974). Entendemos también que Dati fue uno de los primeros en poner en

12 Comunidad ubicada en el río Wawik, afluente del Marañón, situado en el distrito de Imaza (provincia de Bagua, región Amazonas). Centro religioso actualmente activo, aún cuenta con un escaso número de adeptos.

13 Actualmente existen tres comunidades donde se oficia la Iglesia Bíblica Awajún, guiadas por los últimos secuaces de Thomas Dati, todas situadas a lo largo del rio Wawik, afluente del Marañón, distrito de Imaza. 


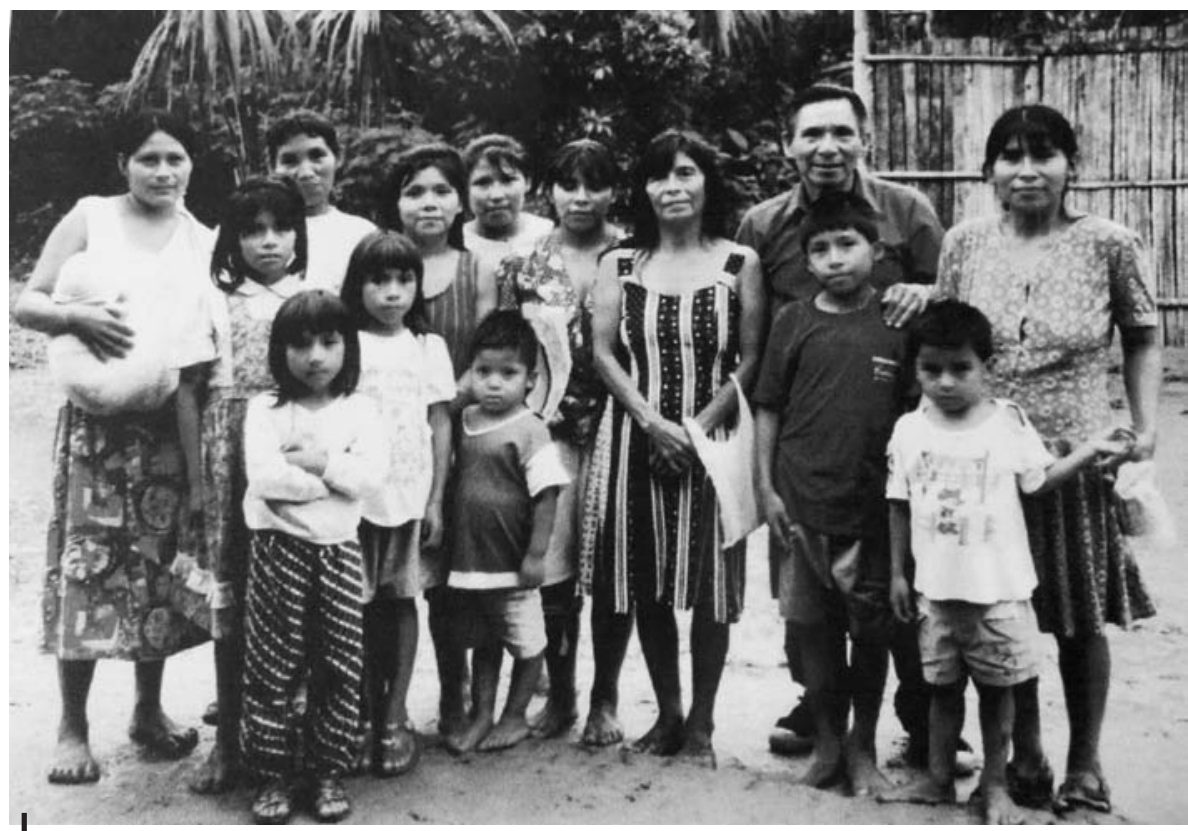

Figura 2 - Thomas Dati con mujeres y niños miembros de la Escuela Bíblica Aguaruna del Alto Marañón (EBAAM) en la comunidad de San Pablo. Años 1990, aproximativamente

(C) Archivo personal de la familia Dati, gentilmente compartido con Silvia Romio para la presente publicación

práctica una particular comunión entre el carisma propio del kakajam y la oratoria propuesta por los predicadores protestantes, aspecto que fue determinante en la consolidación de su autoridad personal.

Dati mostró una capacidad particular en entender cómo las formas expresivas de los misioneros y el espacio de poder que ellos habían construido en las misiones podían volverse recursos para su propio poder personal. Podemos fácilmente suponer que la experiencia de Dati fue parte de un proceso de fusión cultural y de experimentaciones más extensas de su caso particular. Empero, al interior de un panorama de sincretismo religioso extremamente fértil, la experiencia de Dati terminó por distinguirse de las demás por sus dotes personales y por el encuentro con los intereses de algunas misiones extranjeras que decidieron apoyar su ascenso y financiaron sus iniciativas.

Como Priest lo subraya en sus trabajos, los adeptos del IBAY no formularon un lenguaje nuevo en la definición de sí mismos como fieles: más bien, utilizaron expresiones y palabras del vocabulario awajún ya en uso, asignándole significados y contenidos distintos, ligados a la moralidad y a la ética cristiana (Priest, 2003: 97). Dentro de ello, un aporte fundamental fue trazado por el mismo Thomas Dati, quien caracterizó su autoridad por su elocuente uso de la mitología awajún y de sus imágenes. Así fue capaz de ofrecer una vasta gama de historias fundacionales de la ética profesada. La traducción del término de «Dios» por Apajui, personaje 
de la mitología awajún, y la reelaboración de este último en el principal arquetipo de la moralidad indígeno-cristiana, es uno de los máximos ejemplos de este admirable esfuerzo de sincretismo (Priest, 2003: 99-100; Priest, 2007: 146-147).

La reunión de diferentes memorias sobre Thomas Dati nos permite trazar una historia de vida singular. Era capaz de moverse entre diferentes lugares geográficos y múltiples espacios culturales: viajero infatigable y encantador de masas, supo establecer vínculos y proyectos con Iglesias distintas. Luego de la experiencia en la misión nazarena de Larry Garman en el Cenepa (años 1960), él será guía e interprete de los misioneros suizos enviados en las comunidades del Cenepa y de Imaza. En los años siguientes, la invitación a prepararse como profesor bilingüe del ILV lo llevará a Pucallpa. Distinguido por sus dotes carismáticas, recibirá una formación en el Instituto Bíblico de Huánuco como pastor indígena para luego volver a las orillas del Marañón y fundar el Instituto Bíblico Awajún de Yamacay. Su historia de vida nos propone una figura que se desplaza con gran facilitad entre diferentes espacios religiosos: aunque mantenía una cierta propensión hacia los ambientes cristianos, envió a su primer hijo, Isaías, a estudiar en un colegio católico en Trujillo. No manifestaba una preferencia exclusiva hacia una de estas realidades, lo cual demuestra su interés por construir relaciones de alianzas estratégicas. Veía en ellas una posibilidad de consolidación de su éxito personal más que un compromiso de fe o de apego religioso particular.

Encontramos aquí el prototipo de estilo de vida de un «kakajam moderno», es decir una de las primeras personas que, en los años 1970, pusieron en valor los saberes aprendidos a través de las experiencias con los foráneos en espacios urbanos y en las misiones. Con ello propusieron un cambio en las formas de entender y exteriorizar el «poder kakajam» (Romio, 2016). La reelaboración de dichas experiencias y de los conocimientos incorporados se volvió la herramienta principal para trazar nuevos modelos de liderazgo, con capacidad de impactar por la elocuencia de sus discursos y el estilo de vida propuesto. A los modelos anteriores, cuyos puntos centrales eran la matanza del enemigo y la exaltación bélica, se contraponía ahora el ejemplo del hombre temeroso de Dios, devoto de un texto sagrado y capaz de emular el carisma y la performance de un misionero. A esto se sumaba también la posibilidad de viajar a lugares ajenos y de ejercer el mando en diferentes actividades económicas y educativas como los misioneros lo habían hecho en el contexto de la misión.

\section{LA SENSIBILIDAD AWAJÚN FRENTE AL PROCESO DEL «CAMBIO»: LAS EXPERIENCIAS ONÍRICAS}

Para entender en profundidad el proceso de sincretismo desencadenado por la experiencia del IBAY y sus consecuencias en el modelo del «líder religioso» propuesto, es imprescindible cuestionarse sobre el tipo de relación sensible que los individuos habían establecido con esta realidad, y sobre las de transformaciones, en términos de percepción del mundo y de construcción del ser, que se venían forjando. 
Priest mismo, en sus escritos, deja abiertas numerosas cuestiones sobre qué tipo de fe llegaron a profesar los miembros del IBAY, y si era legítimo hablar de «Conversión religiosa» o solamente de grupos relacionados con un jefe carismático, como si fuese un kakajam en tiempos de guerra (Priest, 2003: 106). Cuestiones que nos devuelven a las mismas dificultades que atravesaron todas las experiencias misioneras en la zona, es decir de enfrentarse con el dilema de querer divulgar un discurso de fe ahí donde faltaba una percepción de lo divino tal como venía profesado en el mundo cristiano.

A lo largo de los últimos años se ha difundido un cierto interés en reflexionar sobre las formas en las que los indígenas conversos perciben el tipo de cambio realizado en sus vidas y expresan su relación con el divino (Vilaça, 2011). Es lo que, en los estudios etnográficos más recientes, se define como el problema «de la presencia»: de qué forma los adeptos establecen una relación directa con la divinidad, terminando por ser ellos mismos copartícipes de la revelación del divino (Opas, 2016: 239- 240).

Las modalidades a través de las cuales los indígenas conversos atribuyen una dimensión de materialidad a la concepción de la divinidad y, a través de ello, perciben su integración al interior de sus prácticas cotidianas son diversas. Entre las diferentes formas de «presencias» detectadas, una de las más frecuentes es justamente la comunicación establecida mediante los sueños.

Como pasa en muchas de las sociedades amazónicas, los sueños y su interpretación constituyen una parte importante de las actividades cotidianas de los awajún. Los sueños no solamente constituyen un aspecto integral de la vida cotidiana, sino que, además, representan un momento de revelación de su real identidad: los grupos jíbaros terminan por considerar los sueños como la realidad, mientras que lo vivido sería una simple, y a veces engañosa, representación (Taylor, 1996). Por esta razón, los sueños son considerados el campo de conocimiento profundo de lo cotidiano: la interpretación del contenido de estas experiencias se vuelve la clave para la lectura de la realidad sociopolítica contemporánea del sujeto (Mader, 1999: 69-70; Descola, 1993; Bilhaut, 2011). Algunos estudios recientes subrayan el importante rol jugado por los sueños en la definición de la persona, sus procesos de cambio y la adquisición de saberes particulares: en el campo de la conversión religiosa, el trabajo de Minna Opas pudo evidenciar cómo la experiencia onírica juega un papel absolutamente imprescindible para la comprensión de todo el fenómeno (Opas, 2016: 245).

En aquel tiempo, el hermano Thomas indicó la fecha, en marzo, de los alumnos para aperturar el Instituto. [...] En un sueño se me presenta una voz, que me dice «Marcial», así me dice, me llama por nombre en español, «hoy día es el día de salvación. Si quieres ser salvo, estudia la palabra de Dios». Ese fue! Que me salvó! Por eso yo digo, yo no fui elegido ni por el pueblo o por el pastor. Eso fue lo que me motivó, y me llenó y que nadie o ninguno podía detenerme. Qué yo iba a tomar esa decisión. Cien por ciento yo estaba decidido (Marcial T., Bagua, julio de 2017). 
Este y los demás testimonios recogidos nos presentan un relato enfocado en el recuerdo de una experiencia onírica que hubiera motivado los jóvenes a integrar el IBAY.

En general la memoria no tiende a reproducir, de una forma fiel, la experiencia vivencial tal como ha sido percibida en su momento, sino a dar forma a un relato que pueda ser funcional para la comunicación en el contexto mismo en el cual viene formulado (Candau, 2006). Por esta razón, el análisis siguiente considerará este testimonio no como un esfuerzo de reconstrucción precisa de la experiencia onírica, sino como un elemento que expresa la intencionalidad del orador mientras traduce esa experiencia en este mismo relato.

Es importante señalar que todos los casos observados presentan una descripción de la relación con el divino a través de modalidades que caracterizaban la relación de un waimaku14 con el espíritu ajutap 15 (Brown, 1984: 206). No solamente la experiencia onírica se propone ser la más adecuada para establecer una comunicación con Dios, sino también las formas en la cual esa se desarrolla nos presenta el modelo usual de realización de un jinta ainbau. Con ese término los awajún suelen referirse a un ritual de iniciación bastante consolidado entre todos los grupos jíbaros, donde un individuo se aleja de la sociedad, y se queda en un lugar solitario donde, gracias a una dieta especial y a la toma de plantas alucinógenas, logrará adquirir un estado de conciencia particular que le facilitará el contacto con un ser extrahumano, el ajutap. Según los relatos recogidos, ese espíritu se manifiesta a través de una voz altisonante $y$, bajo forma de mando, trasmite al adepto indicaciones precisas para sus decisiones futuras (Brown, 1984; 1986; Greene, 2009). Por lo tanto, vemos que existe una continuidad entre este tipo de relato y los que son propuestos por los awajún conversos.

En ambos casos se presenta una serie de cambios que evidencian, a mi parecer, las nuevas posturas de definición del «hombre fuerte» al interior de este mundo cultural en transformación. En primer lugar, la voz divina se expresa en castellano. Se trata de un elemento bastante inusual al interior de este género de narración, a tal punto que los mismos testigos tienen que subrayarlo. Podemos entender este aspecto como un signo importante del significado que el idioma castellano, y su representación social, juegan en el imaginario colectivo indígena. El espíritu que se comunica a través de los sueños ya no es un álter ego del adepto (Rubenstein, 2012) o el wakan16 de sus antepasados (Taylor, 1996): él habla un idioma extranjero y se expresa a través de citaciones bíblicas o imágenes ajenas. En segunda lugar, hay que subrayar el contenido mismo del mensaje divino, lo cual no incita a la violencia o al asesinato de un enemigo tal cómo haría la voz del ajutap: se trata de mensajes pacíficos, que proponen un estilo de vida consagrado al estudio de la Biblia y a su difusión.

\footnotetext{
14 waimaku: «persona que había tenido la visión del ajutap» (Brown, 1984: 206).

15 ajutap: «alma de los antiguos guerreros que viven juntos en el cielo» (Brown, 1984: 206).

16 wakan: «la palabra wakan es usada más frecuentemente para designar al "alma"» (Brown, 1984: 207).
} 
En resumen, podemos afirmar que este tipo de relato presenta una forma inédita de entender los ritos de paso, donde los jóvenes tienen que saber entender las palabras de un Ser extrahumano que no proviene de su pasado familiar, sino de otro mundo cultural. El vocabulario y las imágenes movilizadas por este Ser no serían descifrables si la persona no hubiera desarrollado anteriormente los estudios escolares e incorporado conocimientos propios de la sociedad mestiza. Este mensaje nos aclara la finalidad última de dicho relato, la de poner en evidencia el estatus de autoridad y prestigio actualmente ocupado por los mismos oradores, en cuanto «líderes religiosos». Efectivamente, estamos frente a la elaboración, por parte de un grupo de awajún cristianos, ya socialmente afirmados, de un discurso de autoconfirmación social, que permite justificar el camino de formación realizado y, al mismo tiempo, manifiesta la autoridad alcanzada.

Finalmente, encontramos aquí un ejemplo del esfuerzo de hibridación que los «líderes religiosos» están desempeñando a través de la coyuntura de un relato clásico de un waimaku y las expectativas propias de un público cristiano. Efectivamente, uno de los elementos que permite el encuentro cultural entre la cosmología awajún y el lenguaje evangélico reside en la correspondencia del rol que los sueños y la comunicación auditiva asumen en la relación entre lo divino y los profetas. En el Antiguo Testamento, encontramos que la figura de Dios se relaciona con sus profetas a través de una voz imponente y austera, muchas veces en un contexto onírico o acompañada por un acontecimiento natural inesperado ${ }^{17}$. Sabemos también que los propios misioneros, en su esfuerzo de evangelización, solían apropiarse de estos ejemplos para trazar puentes culturales entre los dos mundos, a fin de proponer a sus adeptos un discurso atrayente y una imagen de Dios cercana a las prácticas cotidianas de los neófitos (La Serna, 2009).

Actualmente, encontramos historias que evidencian una etapa ulterior en dicho proceso de sincretismo religioso, donde los adeptos mismos se apropian del lenguaje y de las referencias narrativas misioneras y van construyendo un discurso de autoafirmación y prestigio personal. En el esfuerzo de conjunción de los dos imaginarios distintos, el evangélico termina por ser englobado y reformulado al interior de lo awajún. En otras palabras, el recuerdo de la experiencia sensorial se transforma en la herramienta privilegiada para la confirmación de un estatus social: el orador muestra que su éxito personal ha sido la realización de la voluntad divina. Perspectiva que, a su vez, terminaría por entrelazarse con uno de los aspectos principales de la ética protestante, que ve en el éxito individual un claro indicador de la realización de la voluntad divina.

17 Solo para citar unos de los ejemplos más comunes, podemos mencionar la aparición de Dios a Moisés a través del arbusto ardiente, o las comunicaciones entre Dios y los profetas Abraham, Jacob, Isaías y Jonás. El Nuevo Testamento ofrece una vasta gama de ejemplos similares. 


\section{LOS ACONTECIMIENTOS NATURALES COMO FORMA DE EXPRESIÓN DE LO DIVINO}

Existe una segunda modalidad de narración que los awajún suelen proponer en la descripción de su relación con la divinidad: se trata de la percepción de cambios repentinos del entorno, aspectos que son leídos como mensajes de entidades extrahumanas, útiles para la toma de decisiones importantes. Los individuos se muestran en una posición de atención vigilante hacia el contexto externo, donde la lectura rápida de cualquier tipo de acontecimiento se transforma en una herramienta fundamental para la realización de su camino personal. Entre las diferentes gamas de posibilidades, hay unos temas bastantes recurrentes: es decir el allanamiento de un evento atmosférico o ambiental que rompe con la tranquilidad cotidiana, o una condición de enfermedad que quiebra el bienestar psicofísico del interesado. Estas manifestaciones ponen al individuo en una condición de riesgo que será superada solamente con la toma de una decisión impactante, como la de cambiar de estilo de vida e integrarse a una Iglesia. En ese sentido, la decisión de entrar a formar parte de la Iglesia y de elegir el estilo de vida profesado por Thomas Dati, se interpretan como respuesta a una de estas experiencias.

Yo me fui para recibir la vacuna, y en medio del camino, me pica una culebra. Lamentablemente, era tarde y en tiempo de lluvia. Nos enteramos que el hermano Thomas estaba por San Pablo. Lo llamamos para que nos mande una canoa, pero no fue así. Yo tenía en la pulsera una pie de Iguana, contra las picaduras de culebra. [...] y funcionó. Y con eso digo que me sentí que el Señor estaba presente al costado de mí, que sino hubiera muerto. Al día siguiente llegué a la comunidad de Thomas Dati, donde me quedé unos meses para mi convalecencia. Es ahí cuando yo conocí el Instituto, para la preparación de pastores. (David T., comunidad de Nazareth, junio de 2017).

El análisis de este y otros testimonios nos permite reflexionar sobre dos de los principales aspectos que definen el concepto de persona y la relación que ella establece con lo divino. En primer lugar, encontramos una pronunciada atención en el «ego narrador», protagonista de la decisión y situado en el centro del relato. Se trata de una individualidad fuertemente marcada, llamada a discernir rápidamente los acontecimientos que se presentan antes sus ojos y, por lo tanto, tomar una decisión consecuente. El individuo es percibido como viviendo al interior de un microcosmo vivo que lo introduce improvisadamente en una condición de miedo e inseguridad, poniendo a prueba sus capacidades de reacción y de lectura de los eventos. Numerosos son los estudios etnográficos que evidencian cómo los grupos jíbaros consideran las situaciones límites como las más idóneas para forjar la identidad de un individuo fuerte: la confrontación con sus miedos sería la clave para la consolidación de una cierta fortaleza interior (Mader, 1999: 175, 428). Se trata de esa misma condición vivencial que Turner define como la etapa de «marginalidad» (Turner, 1966) que obliga al individuo a enfrentar diferentes géneros de dificultades y sufrimientos, agudizados por una situación de soledad y 
por una dieta alimenticia particular. Los awajún consideran que estas circunstancias permiten al joven entrar en contacto con su Ego interior y tomar conciencia de sus capacidades innatas, experiencia que podrá motivarlo a seguir un camino de kakajam. Una vez más, encontramos en esta forma de toma de decisiones, una reelaboración, por parte de los indígenas, no solamente de la postura clásica del kakajam, sino también de las expectativas propias del ambiente cristiano, donde la adhesión a una Iglesia respondería a la «llamada de Dios». Lenguaje religioso y capacidad de decisión del «hombre fuerte» se reúnen entonces en la definición del «líder religioso», donde la exclusividad de una relación particular y directa con lo divino consagraría su propia autoridad.

En segundo lugar, a la luz de los estudios hasta ahora realizados, vemos cómo la idea de cambio es inherente a la percepción awajún del individuo y su forma de modelar su trayectoria de vida. El individuo es concebido como un ser dinámico, capaz de reformular constantemente su manera de estar en el mundo, a partir de las condiciones que percibe como las más adecuadas. Él se mueve al interior de un microcosmo hecho de sensaciones, voces, y fuerzas extrahumanas, con las cuales mantiene una relación de diálogo. Dentro de la perspectiva awajún, la decisión de pasar a ser miembro de una Iglesia cristiana no modifica esta forma de percibir el mundo, más bien ofrece unas herramientas específicas para entender esos elementos extranaturales con los cuales ya antes establecía relaciones. La decisión de ser miembro de una Iglesia no constituye un evento excepcional de por sí, más bien corresponde a las expectativas colectivas hacia una figura de «líder», es decir un sujeto poseedor de una personalidad capaz de tomar decisiones fuertes y mostrar ejemplos siempre distintos de expresión del poder. Si el líder es quien «logra abrir siempre nuevos caminos»18, encontramos aquí una clara predisposición a buscar, en modelos o imágenes ofrecidas por el contexto externo, fuentes de inspiración para expresiones siempre distintas del estatus de poder y autoridad. En ese sentido, el modelo propuesto por Thomas Dati y su vida han tenido que impactar profundamente en las visiones y expectativas de diferentes jóvenes, llevándolos en poco tiempo a ser parte del IBAY y a reproducir este modelo de liderazgo.

\section{CONCLUSIONES}

A lo largo del artículo hemos podido analizar diferentes prácticas y formas expresivas adoptadas en el IBAY que han puesto en evidencia el esfuerzo de los awajún evangélicos por entender los procesos de cambio vividos en su sociedad a partir de la penetración de elementos cristianos, sobre todo en los términos de construcción del «kakajam moderno» y su posición en una sociedad pacificada. Estamos frente a la propuesta de un modelo singular de «jinta ainbau», donde el estudio de los textos sagrados y la relación preferencial con Dios se volvieron elementos cardinales de un estatus de poder particular, el del «líder religioso». 


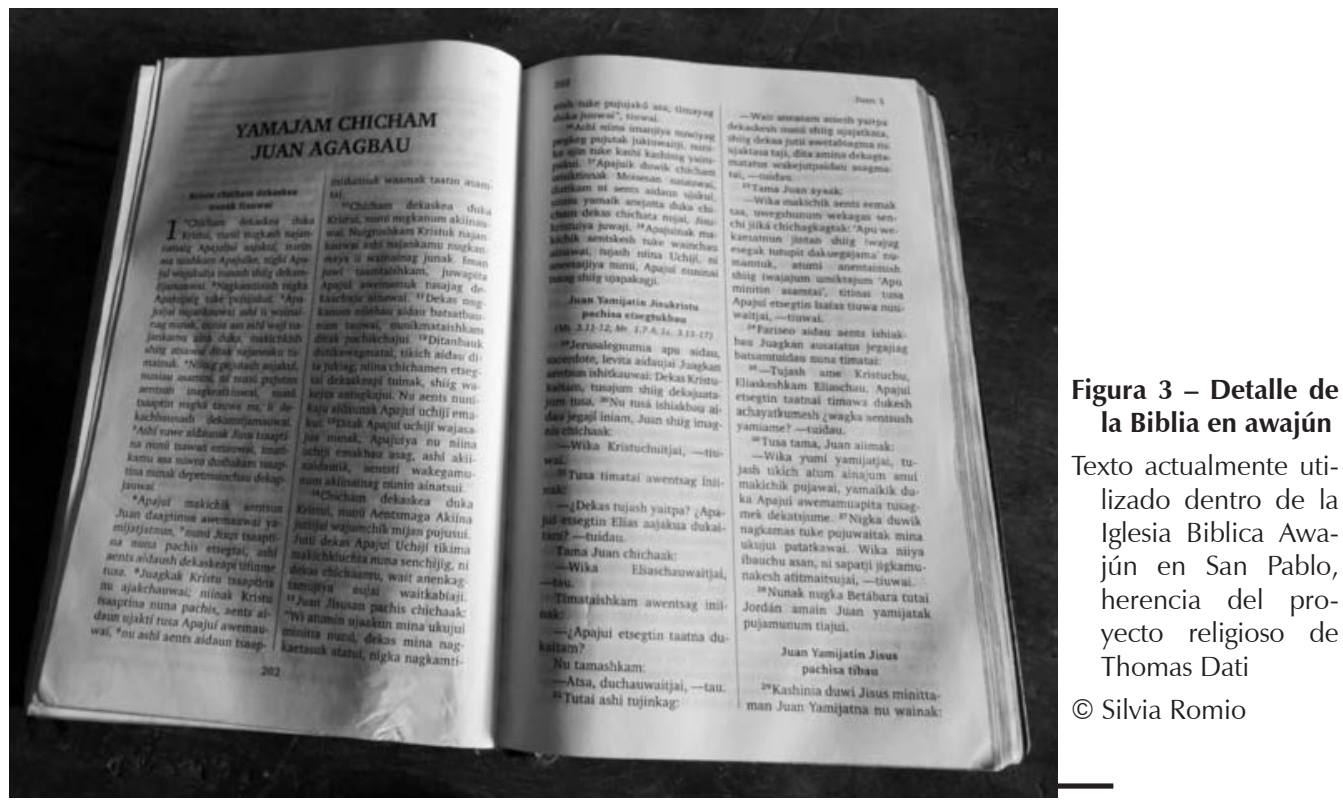

¿Por qué el modelo de «líder religioso» no alcanzó el mismo éxito entre los awajún frente a los otros modelos de «kakajam moderno»? En la actualidad, vemos que ni los hijos de Dati y ni sus adeptos más próximos han seguido sus huellas; la Iglesia Bíblica Awajún está guiada por figuras dotadas de escaso carisma y que no promueven un discurso religioso innovador. La respuesta, quizás, resida en el estrecho vínculo que se mantuvo, desde un comienzo, entre el estudio de la Biblia y los poderes de curación conexos. Tanto los nazarenos como el resto de experiencias misioneras intentaron fortalecer su proselitismo con la perspectiva de las capacidades de curación que las oraciones y el conocimiento de los textos sagrados podían ofrecer al predicador. Lamentablemente, ese tipo de discurso terminó por definir un poder religioso que entraba en competición con el de la brujería, es decir el dominio de la salud y la enfermedad, de la vida y la muerte de los demás19. No es casual que el compañero de estudios de Thomas Dati, una vez acabada su formación como «líder religioso», terminó asesinado en su propia comunidad, acusado de brujería. Este caso dejó un antecedente importante en la conciencia awajún de la zona, al punto que suele ser recordado en asociación con la figura de Thomas Dati, como su posible Álter Ego, elemento que seguramente debilitó el modelo de liderazgo propuesto por el IBAY.

Este primer predicador es recordado por su peculiar interés en escribir un libro sobre brujería una vez culminada la traducción de la Biblia al awajún: «en cómo entrar a ser brujo y salir de eso» (David T., comunidad de Nazareth, junio de 2017). El estatus adquirido por los saberes contenidos en los textos sagrados parece, 
en su caso, asociarse con la idea que el texto escrito permite el dominio sobre las fuerzas extrahumanas (véase fig. 3). Vemos, por lo tanto, que la capacidad awajún de reelaboración del discurso religioso terminó por fomentar imágenes y mecanismos sociales que pronto se escaparon de la mano de los misioneros y llegaron a mezclarse con los espacios manejados por la brujería, fuentes de atracción y amenaza a la vez. El peligro de que los saberes incorporados a través de la «comprensión profunda» de la Biblia podían llevar a la adquisición de poderes oscuros empezó a difundirse entre los creyentes awajún dejando abiertas tormentosas pesadillas, que el mensaje y la práctica cristianos no terminaron de resolver.

\section{Referencias citadas}

BILHAUT, A.G., 2011 - El sueño de los záparas. Patrimonio onírico de un pueblo de la Alta Amazonía, 376 pp.; Quito: Facultad Latinoamericana de Ciencias Sociales (FLACSO), Abya Yala.

BROWN, M., 1984 - Una paz incierta. Historia y cultura de las comunidades aguarunas frente al impacto de la carretera marginal, 280 pp.; Lima: Centro Amazónico de Antropología y Aplicación Práctica ( CAAAP).

BROWN, M., 1986 - Tsewa's gift. Magic and Meaning in an Amazonian Society, 222 pp.; Washington \& London: Smithsonian Institution Press.

BROWN, M., 2014 - Upriver: The Turbulent Life and Times of an Amazonian People, 321 pp.; Cambridge, Massachusetts \& London, Harvard University Press.

CANDAU, J., 2006 - Antropología de la memoria, 128 pp.; Buenos Aires: Edición Nueva Visión.

CLASTRES, P., 1974 - La société contre l'État. Recherches d'Anthropologie politique, 192 pp.; París: Les Éditions de Minuit.

DESCOLA, P., 1993 - Les lances du crépuscule. Avec les Indiens Jivaros de haute Amazonie, 485 рp.; París: Plon.

GARRA, S., 2017 - Les sorciers condamnés : chamanisme et mutation dans le monde awajún (Amazonas, Pérou), 417 pp.; París: Université Paris Nanterre. Tesis de doctorado.

GREENE, S., 2009 - Caminos y carreteras: acostumbrando la indigenidad en la selva peruana; 308 pp.; Lima: Instituto de Estudios Peruanos (IEP).

GUALLART, J. M., 1990 - Entre pongo y cordillera: historia de la etnia aguaruna huambisa, 258 pp.; Lima: Centro Amazónico de Antropología y Aplicación Práctica ( CAAAP).

LA SERNA, J. C., 2009 - Más allá de la parusía: el enfrentamiento al demonio en el bosque: religión, política y sociedad asháninka a través de la presencia misionera adventista en la selva central peruana (1920-1990), 213 pp.; Lima: Universidad Nacional Mayor de San Marcos (UNMSM). Tesis de Maestría.

MADER, E., 1999 - Metamorfosis del poder: persona, mito y visión en la sociedad de Shuar y Achuar (Ecuador, Perú); 462 pp.; Quito: Editorial Abya Yala.

OPAS, M., 2016 - Dreaming Faith into Being: Indigenous Evangelicals and Co-acted Experiences of the Divine. Temenos, 52 (2): 239-260.

PRIEST, R., 1993 - Defilement, Moral Purity and Transgressive Power: The symbolism of Filth in Aguaruna Jivaro Culture, 636 pp.; Berkeley: University of California. Tesis de Doctorado. 
PRIEST, R., 2003 - "I Discovered My Sin !" Aguaruna Evangelical Conversion Narratives. In: The Anthropology of Religious Conversion (A. Buckser \& S. Glazier, eds.): 95-108; Nueva York, Toronto, Oxford : Rowman \& Littlefield Publishers.

PRIEST, R., 2007 - Worship in the Amazon: the case of the Aguaruna Evangelical Church. In: Christian Worship Worldwide: Expanding Horizons, deepening Practices (C. E. Farhadian, ed.): 131-155; Grand Rapids, Mich.: William B. Eedmans Publishing Company.

ROMIO, S., 2016 - El viaje hacia la ciudad. Caminos de vida, camino para el poder. La nueva forma del ritual de iniciación entre los Awajún (1930-1960)». In: Apus, Caciques y Presidentes. Estado y política indígena amazónica en los países andinos (A. Surrallés, Ó. Espinosa \& D. Jabin, eds.): 61- 80; Lima: IWGIA, IFEA, PUCP.

ROMIO, S., 2017 - "Suivre le chemin". La construction de l'identité politique des Awajún d'Amazonie Péruvienne (1920-1980); París: École des Hautes Études en Sciences Sociales. Tesis de doctorado.

RUBENSTEIN, S., 2012 - On the Importance of Vision among the Amazonian Shuar. Current Anthropology, 53 (1): 39-79.

SEEGER, A., DA MATTA, R. \& VIVEIROS de CASTRO, E., 1979 - A construção da pessoa nas sociedades indígenas brasileiras. Boletim do Museu Nacional, 32: 2-19.

STOLL, D., 1990 - ¿America Latina se vuelve protestante? Las políticas del crecimiento evangélico, 442 pp.; Berkeley: University of California Press.

TAYLOR, A. C., 1996 - The Soul's Body and Its States. An Amazonian Perspective on the Nature of Being Human. The Journal of the Royal Anthropological Institute, 2 (2): 201-215.

TURNER, V., 1966 - The Ritual Process: Structure and anti-Structure (Lewis Henry Morgan Lectures), viii + 213 pp.; New York: Cornell University Press. Cornell Paperbacks.

VILAÇA, A., 2005 - Chronically Unstable Bodies: Reflections on Amazonian Corporalities. Journal of the Royal Anthropological Institute, 11 (3): 445-464.

VILAÇA, A., 2011 - Dividuality in Amazonia: God, the Devil and the constitution of personhood in Wari' Christianity. Journal of the Royal Anthropological Institute, 17 (2): 243-262.

WINANS, R., 1955 - Cospel over the Andes: Notes of Roger S. Winans, 141 pp.; Kansas City: Beacon Hill Press. 